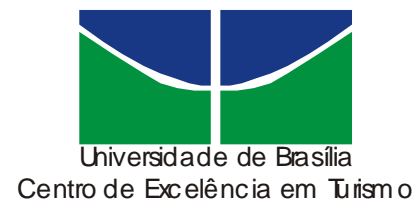

\title{
O CCBB como um espaço turístico cultural de Brasília
}

Gilka Pinto de Lemos

Professora Doutora Deis Elucy Siqueira

(orientadora)

Monografia apresentada ao Centro de Excelência em Turismo da Universidade de Brasília como requisito parcial para a obtenção do certificado de Especialista em Turismo: cultura e lazer.

Brasília - DF, junho de 2005. 


\section{UNIVERSIDADE DE BRASÍLIA}

Centro de Excelência em Turismo

Curso de Especialização em Turismo: cultura e lazer

\section{O ССВB como um espaço turístico cultural de Brasília}

Gilka Pinto de Lemos

Banca Examinadora:

Professora Doutora Deis Elucy Siqueira (orientadora)

Professora Doutora Mariza Veloso (membro)

Brasília, junho de 2005. 


\section{Resumo}

Os Centros Culturais Banco do Brasil - CCBBs, em funcionamento nas cidades do Rio de Janeiro, Brasília e São Paulo, e em fase de implantação em Recife, consistem no principal instrumento de ação do Banco do Brasil na área da cultura: oferecem regularmente programação diversificada e de qualidade. Com isso, têmse tornado importante referência cultural, incluindo-se entre as atrações turísticas dessas capitais.

Com o presente trabalho, buscou-se compreender o papel desempenhado pelo CCBB Brasília no roteiro turístico cultural da cidade, o que foi feito por meio da identificação e análise de seu público, da coleta de informações sobre sua estrutura e funcionamento e, ainda, por meio da avaliação da programação cultural oferecida,

Palavras-chave: CCBB, Turismo cultural, Centro cultural, Patrimônio cultural, Lazer cultural. 


\begin{abstract}
The "Centros Culturais Banco do Brasil - CCBBs", operating in Rio de Janeiro, Brasília and São Paulo and also soon in Recife, are the main instrument of action of Banco do Brasil in the cultural area: they offer, regularly, a qualified and diversified programme. Lately, they became important cultural reference and have been included among tourist attraction places in these cities.
\end{abstract}

This paper has been done with the aim of understanding the role of CCBB in Brasilia's cultural tourism circuit. This was lead by the means of identifying and analysing its public and of information collected about its structure and operation, as well as the evaluation of its programme.

Key Words: CCBB, Cultural tourism, Cultural center, Cultural property, Cultural leisure. 


\section{Lista de Apêndices}

1 - Entrevista com o Gerente Geral do CCBB Brasília

2 - Modelo de questionário

3 - Planilha Geral

4 - Tabela: Profissões

5 - Tabela: Totalizações

6 - Tabela: Eventos que mais interessam na programação do CCBB Brasília

7 - Tabela: Pontos turísticos

8 - Tabela: Pessoas que indicaram o CCBB como ponto turístico

9 - Tabela: Turistas 


\section{Lista de Anexos}

1 - Notícia veiculada no site do CCBB - Prêmio UPIS de Turismo

2 - Relatório Perfil do Público CCBB Brasília 2004 


\section{Sumário}

1) Introdução $\ldots \ldots \ldots \ldots \ldots \ldots \ldots \ldots \ldots \ldots \ldots \ldots \ldots$

1.1 Objetivo $\ldots \ldots \ldots \ldots \ldots \ldots \ldots \ldots \ldots \ldots$

1.2 Problema de pesquisa $\ldots \ldots \ldots \ldots \ldots \ldots . \quad 10$

1.3 Metodologia ..................... $\quad 10$

2) Estudo de caso: O CCBB Brasília .............. 14

2.1 Conhecendo o CCBB Brasília ............. 14

- Histórico ........................ 14

- Estrutura funcional $\ldots \ldots \ldots \ldots \ldots \ldots \ldots . . \ldots$

- Política cultural ...................... 16

- Público-alvo ...................... 18

- Processo de inscrição de projetos ........... $\quad 20$

- Programação ....................... 21

- Programa Educativo .................. $\quad 22$

2.2 O público freqüentador do CCBB Brasília. ..... 23

2.3 CCBB, turismo e lazer. . . . . . . . . . . . . . $\quad 28$

3) Considerações finais . . . . . . . . . . . . . . . . 35

Apêndices............................. $\quad 37$

Anexos............................... $\quad 67$

Referências Bibliográficas $\ldots \ldots \ldots \ldots \ldots \ldots \ldots \ldots . \quad 91$ 


\section{1) Introdução}

Esta monografia se ancora em um estudo de caso sobre o Centro Cultural Banco do Brasil em Brasília (CCBB Brasília ${ }^{1}$ ), importante espaço cultural do local, cujo público freqüentador será identificado e analisado, para que se possa compreender a sua importância para o roteiro turístico cultural da cidade.

Os Centros Culturais do Banco do Brasil estão hoje instalados nas cidades do Rio de Janeiro (1989), Brasília (2000), São Paulo (2001) e Recife (em andamento). No Rio de Janeiro, São Paulo e Recife, a escolha dos prédios refletiu a preocupação de revitalizar pontos importantes nos centros históricos daquelas localidades e de alcançar uma parcela da população que não tem acesso aos meios culturais e que não costuma freqüentar exposições e shows.Tais prédios situam-se em locais de acesso facilitado por linhas de ônibus e de metrô, não obstante também contem com estacionamento próprio para os veículos de seus visitantes.

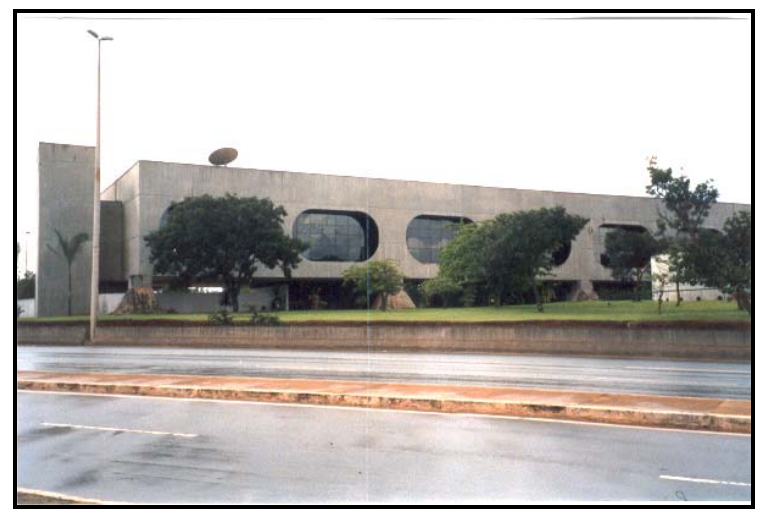

Fonte: Gilka Lemos/2005

Diferentemente, o CCBB Brasília ocupa um moderno prédio projetado por Oscar Niemeyer $^{2}$, o qual, por razões decorrentes do peculiar projeto arquitetônico e

\footnotetext{
${ }^{1}$ O CCBB Brasília já foi procurado por estudantes das áreas de administração, comunicação social e turismo que pretendiam ter o Centro Cultural como tema de suas monografias de final de curso. Entretanto, não há como conhecer quais as abordagens desses trabalhos, uma vez que a instituição não dispõe de contato com essas pessoas nem recebeu qualquer exemplar das monografias.

${ }^{2}$ Todas as fotos inseridas neste trabalho foram tiradas no prédio do CCBB Brasília.
} 
urbanístico da cidade, fica situado em setor distante da área central, o que não facilita, em princípio, o acesso de pessoas que dependem do transporte público, muito embora o local seja servido por linha regular de ônibus. O Centro Cultural foi inaugurado em 12 de outubro de 2000 com o intuito de desempenhar as funções de responsabilidade social do Banco do Brasil no âmbito da cultura e de implementar ações de marketing cultural na Capital Federal.

O CCBB Brasília apresenta-se como um espaço multidisciplinar onde várias vertentes artísticas e culturais se cruzam. Ele objetiva estimular a produção local de cultura e democratizar o acesso da população à arte, ou seja, pretende atingir parcelas cada vez maiores da população com a promoção de eventos regulares de qualidade. Além disso, ao buscar e treinar mão-de-obra local para funções ligadas aos eventos que realiza, provoca a dinamização do mercado de trabalho para os setores cultural e de lazer.

O primeiro Centro Cultural inaugurado pelo Banco do Brasil, o CCBB RJ, completou 15 anos de atividades em outubro de 2004. Nesse período, tornou-se referência no cenário nacional pela qualidade, regularidade, diversidade e acessibilidade de sua programação, tendência que vem sendo naturalmente acompanhada pelos CCBBs de São Paulo e Brasília.

Esses Centros Culturais se tornaram verdadeiros pólos de cultura, arte e educação. São freqüentados por pessoas de todos os segmentos das comunidades em que atuam e por visitantes das diversas partes do Brasil e do mundo. Em 2003, o conjunto dos CCBBs recebeu 2,8 milhões de visitantes. Em 2004, o número apurado foi de 3,7 milhões.

O CCBB Brasília recebeu 226 mil pessoas em 2003 (8\% do total dos visitantes em todo o país). Em 2004, foi visitado por um público de 404 mil pessoas (11\% do total), revelando um crescimento de $78 \%$ no ano e de $3 \%$ na sua participação em 
relação aos visitantes de todos os CCBBs. Nesse mesmo ano, São Paulo recebeu 872 mil pessoas e o Rio de Janeiro, 2.452 mil.

Desde o lançamento do primeiro CCBB foram recebidos mais de 30 prêmios institucionais, dentre eles o Prêmio UPIS de Turismo, concedido ao CCBB Brasília em 27/9/2004. Tal prêmio foi criado com o objetivo de homenagear profissionais e organizações que têm contribuído para o desenvolvimento do setor turístico no Brasil, e o CCBB Brasília foi escolhido por unanimidade pela Comissão Julgadora, em razão dos excelentes serviços prestados pela instituição à cidade ${ }^{3}$.

\subsection{Objetivo}

Com esta pesquisa, busca-se compreender o papel desempenhado pelo CCBB dentro do roteiro turístico cultural de Brasília. A fim de atingir esse objetivo, pretende-se: 1) identificar o perfil dos seus freqüentadores; 2) analisar esse público freqüentador; 3) ter uma visão da estrutura e funcionamento do CCBB Brasília e 4) conhecer a programação e os programas existentes.

\subsection{Problema de pesquisa}

Qual é o papel do CCBB no roteiro turístico cultural de Brasília.

\subsection{Metodologia}

O presente trabalho foi realizado a partir de um estudo de caso sobre um espaço cultural de Brasília. Foi ancorado em uma pesquisa realizada com base em questionários semi-abertos e entrevistas semidirigidas, tendo como lócus da investigação o CCBB Brasília, a qual foi complementada por pesquisas bibliográfica e documental.

\footnotetext{
${ }^{3}$ Ver Anexo 1 - Notícia veiculada no site do CCBB.
} 
Para obter uma visão da estrutura e do funcionamento do CCBB Brasília e conhecer a programação e os programas existentes para esse espaço cultural, foi realizada uma entrevista com o Gerente Geral da instituição e seu Assessor de Imprensa, a qual se encontra transcrita e constitui o Apêndice 1. Com o Assessor de Imprensa, foram mantidos diversos outros contatos, tanto presenciais quanto via correio eletrônico (e-mail). Foram consultadas, ainda, as publicações da própria instituição e as informações por ela fornecidas em atenção a solicitações especificamente formuladas pela autora do presente trabalho.

Os dados para identificação e análise do perfil dos freqüentadores foram coletados por meio da aplicação de questionário cujo conteúdo está reproduzido no Apêndice 2. A população-alvo desse questionário foi formada pelos freqüentadores espontâneos do CCBB Brasília, ou seja, aquele público não vinculado a programas específicos tais como o Programa Educativo, sobre o qual apenas será feito um breve relato no desenvolvimento deste trabalho (item 2.1).

A amostra foi constituída de 150 questionários, aplicados da seguinte forma:

- 77 questionários, no período de 2 a 7/11/2004, correspondendo a 3,31\% do total de visitantes da última semana da exposição "Entre duas modernidades do Neoclassicismo ao Pós-impressionismo" (2.329 pessoas);

- 73 questionários, no período de 23 a 28/11/2004, correspondendo a 7,64\% do total de visitantes da primeira semana da exposição "Onde está você, Geração 80?" (956 pessoas).

Exceto no primeiro dia da pesquisa, quando o horário de permanência no local foi de 6 horas (das 13 às 19 horas), nos demais dias esse horário girou em torno de duas horas, sempre no final da tarde, geralmente entre as 17 e as 19 horas. 


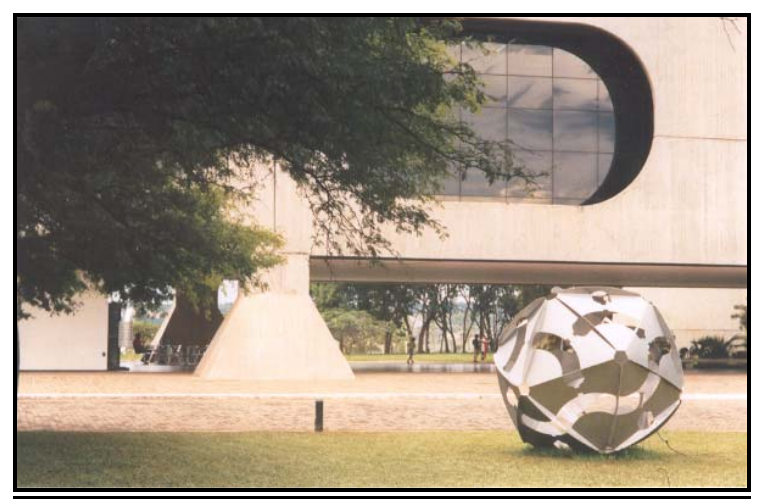

Fonte: Gilka Lemos/2005

Os questionários foram aplicados na Praça de Eventos do CCBB Brasília (fotos desta página) - uma área externa com aproximadamente $1.500 \mathrm{~m}^{2}$, localizada sob os pilotis do prédio e utilizada, como uma alternativa aos espaços fechados do CCBB, para exposições, performances, apresentações teatrais e instalações, bem como para abrigar espaços especialmente montados para música ou teatro, como tendas, palcos etc.

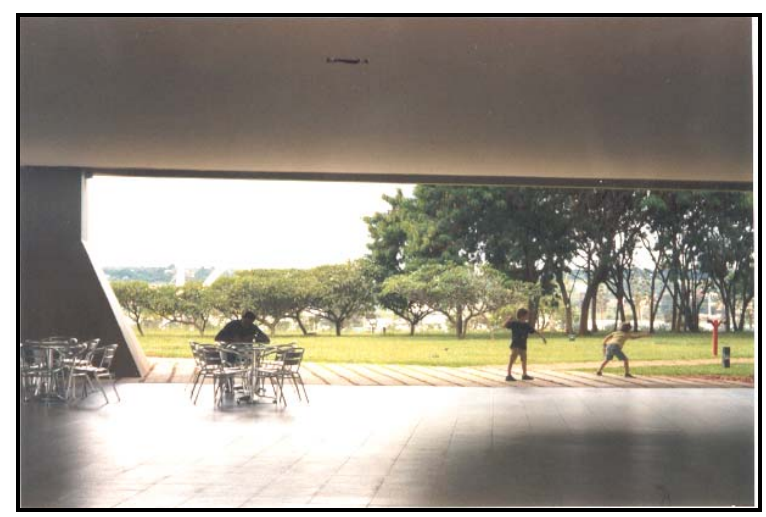

Fonte: Gilka Lemos/2005

Com uma rápida explanação do objetivo do trabalho, a pesquisadora solicitava o preenchimento do questionário, entregava os formulários às pessoas e se retirava, só abordando os pesquisados novamente ao final, para recolher os questionários já respondidos. 
Esta monografia está estruturada em três capítulos. O primeiro apresenta o CCBB Brasília: sua história, como funciona e o que oferece ao público. No segundo, é feita uma análise do público freqüentador desse espaço cultural a partir dos resultados da pesquisa, delineando-se o seu perfil. No último capítulo, procura-se compreender o papel do CCBB no roteiro turístico cultural de Brasília a partir das opiniões coletadas junto a esse público freqüentador.

As análises foram realizadas tomando-se por base os conceitos de cultura, turismo cultural, patrimônio cultural e lazer, sobretudo a partir das visões dos seguintes autores: Mike Featherstone (1995), Silberberg (1995), Carlos Delphim (2004), Jofre Dumazedier (2000). 


\section{2) Estudo de caso: O CCBB Brasília}

\subsection{Conhecendo o CCBB Brasília}

\section{Histórico}

O prédio onde se encontra instalado o CCBB Brasília foi inaugurado em 1984 com o objetivo de abrigar a área de Recursos Humanos do Banco do Brasil, especificamente o seu Centro de Formação. Ainda não se previa, na época, um Centro Cultural. O primeiro CCBB foi aberto somente em 1989, no Rio de Janeiro, depois que a sede do Banco foi transferida para Brasília. O prédio onde então funcionava a sede do Banco, que era de sua propriedade e tinha um excelente acervo de literatura e de obras de arte, recebeu uma destinação cultural. O Banco do Brasil decidiu investir em uma política mais consistente de apoio à cultura, saindo dos patrocínios diretos de exposições ou de determinados espetáculos de teatro e música. Resolveu fundar um Centro Cultural que abrangesse todas as áreas da cultura, e que veio a se tornar um padrão de CCBB.

O CCBB Brasília só foi inaugurado em 2000, como resultado de uma séria política de investimento em cultura que passou a ser adotada pelo Banco do Brasil considerando a necessidade de levar a sua atuação cultural a outras cidades do país. A escolha da localização em de Brasília seguiu a diretriz de serem utilizadas instalações do próprio Banco, e o prédio ocupado pelo Centro de Formação surgiu como o mais adequado, especialmente pela sua arquitetura: trata-se de um belíssimo projeto arquitetônico de Oscar Niemeyer.

De início, foram feitas as adaptações para transformar o auditório existente em teatro e foram abertas as galerias de exposições, ocupando o local onde funcionava a biblioteca do Centro de Formação, que foi transferida para outro lugar do prédio. Na época, o CCBB Brasília era apenas um espaço cultural, "não 
tinha a mesma característica do CCBB RJ de ser multicultural, de abranger todas as áreas" 4.

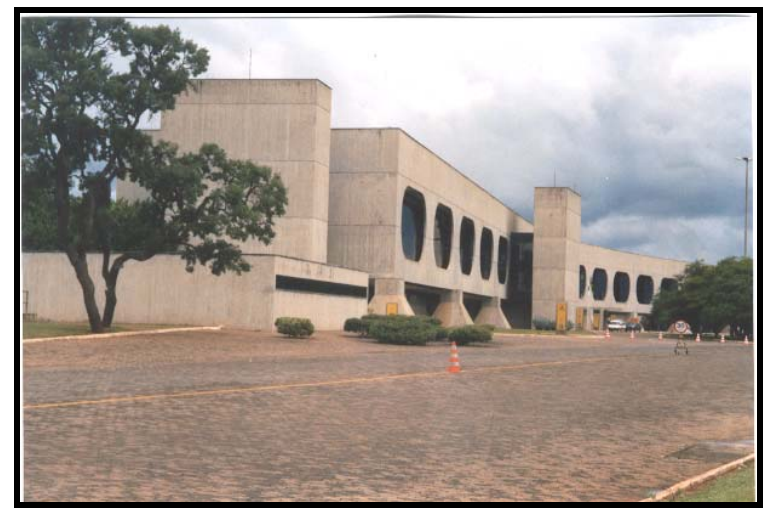

Fonte: Gilka Lemos/2005

Em 2002, diante da boa resposta dada pelo CCBB Brasília em termos de freqüência de público, decidiu-se por implantar, aqui, o modelo adotado no Rio de Janeiro e São Paulo, este último inaugurado em 2001. A partir de então, foram criados uma sala de cinema, uma livraria, um café-bistrô e mais uma sala para receber exposições de maior porte.

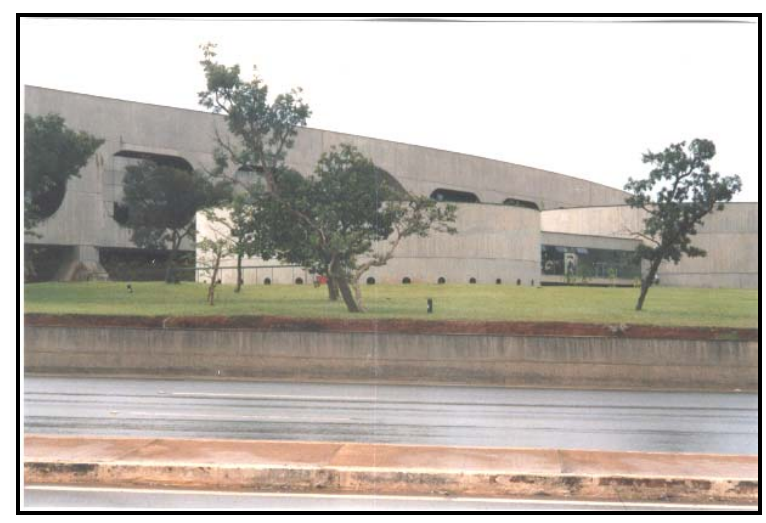

Fonte: Gilka Lemos/2005

${ }^{4}$ Ver Apêndice 1 - Entrevista com o Gerente Geral do CCBB Brasília. 
As dificuldades de localização do CCBB Brasília têm sido minimizadas. A Ponte $\mathrm{JK}$, inaugurada no início de 2003 , tornou-se um ponto turístico bastante visitado e o prédio do $\mathrm{CCBB}$, situado bem perto, ganhou visibilidade, não só para os moradores da cidade, como para os turistas vindos de outras partes do país.

Outro aspecto a se considerar é sua proximidade com a Academia de Tênis, formando uma espécie de "corredor cultural". A Academia oferece, entre outras opções nas áreas da gastronomia e da música, uma excelente programação de cinema alternativa ao circuito comercial, em diversas salas de exibição.

\section{Estrutura funcional}

O CCBB Brasília é uma gerência vinculada à Gerência Executiva de Marketing Institucional, a qual integra a Diretoria de Marketing e Comunicação do Banco do Brasil S/A. A estrutura do CCBB é dividida em três Gerências de Núcleo (de Administração, de Programação e de Planejamento e Comunicação), todas subordinadas ao Gerente Geral do CCBB.

\section{Política cultural}

As ações do Banco do Brasil na área da cultura têm os seguintes objetivos:

- agregar à marca BB valores de excelência, compromisso socioambiental e inovação;

- implementar as ações de marketing cultural do BB no espaço onde atua;

- potencializar a realização de negócios para o Conglomerado BB;

- proporcionar o acesso à cultura aos diversos segmentos sociais;

- contribuir para o desenvolvimento artístico-cultural da sociedade brasileira.

São três as formas de atuação do Banco nessa área. Uma delas é através da Fundação Banco do Brasil, que é mais voltada para o social, para a geração de emprego e renda, mas que também tem o seu lado cultural. Destaca-se o Projeto Memória. Dirigido às escolas, o projeto homenageia e divulga, a cada ano, a obra de uma grande personalidade da cultura brasileira. 
Outra forma de ação se dá através dos denominados "Patrocínios de oportunidade". Trata-se de pedidos que chegam ao Banco do Brasil aleatoriamente e que são analisados pela Diretoria em procedimento à parte do processo regular de inscrição de projetos via CCBBs ou Circuito Cultural. Sua aprovação depende dos interesses de marketing institucional. Esses projetos não chegam a $10 \%$ dos investimentos do Banco na área cultural.

A mais preponderante forma de atuação - já que é responsável por cerca de $80 \%$ dos investimentos do Banco em cultura ${ }^{5}$ - se dá por meio dos Centros Culturais Banco do Brasil. Tanto é que existe um projeto de expansão que prevê a abertura de pelo menos mais dois Centros Culturais, além do que está por ser inaugurado em Recife. E para as cidades onde não há um CCBB criou-se, em 1999, um projeto chamado Circuito Cultural Banco do Brasil, um CCBB itinerante que percorre quase todas as capitais do país e algumas cidades do interior, conforme as suas razões de relacionamento: se o Banco precisa empreender uma ação naquela cidade, imprimir uma imagem mais forte naquele local, leva o circuito para lá.

O Circuito, a exemplo dos CCBBs, apresenta todos os segmentos culturais: música, artes cênicas (teatro e dança), exposições (artes plásticas e fotografia), programas educativos (oficinas, seminários, palestras etc.) e mostras audiovisuais. A escolha dos projetos para o Circuito Cultural é feita em processo distinto daquele relativo à seleção da programação dos Centros Culturais. Desde que se iniciou, o Circuito percorreu 32 cidades em 113 etapas, atraindo um público superior a um milhão de pessoas.

Os parceiros são fundamentais para o sucesso dos CCBBs. Esse apoio concedido garante vantagens aos parceiros: renúncia fiscal prevista na Lei de Incentivo à Cultura; aliar sua marca a projetos culturais de qualidade, com visibilidade nos

\footnotetext{
${ }^{5}$ Idem, Nota 4.
} 
materiais de divulgação dos eventos; cota de ingressos para filmes e espetáculos; e espaço cedido para a realização de eventos institucionais.

Dentro dessa política de atuação, não estão previstos o patrocínio isolado de livro, filme ou CD nem a associação da marca CCBB a empresas de armamento, fumo ou bebidas alcoólicas.

\section{Público-alvo}

Os CCBBs tendem a retratar, na forma como atuam, a estratégia do Banco do Brasil de procurar atender a todos os segmentos da sociedade. "A gente procura ser um Centro Cultural de todos, independente de idade, de posição social, de gosto, porque a gente faz desde o clássico ao popular, ao erudito, passando por tudo, música eletrônica, música instrumental, música popular brasileira, samba. Você pode ver pela nossa programação que ela tem que ter esse mix"6.

A diversidade da programação, que abrange todas as manifestações culturais, estilos e movimentos artísticos, é um valor estratégico para o CCBB. Isso é uma orientação nacional. Os outros valores estratégicos perseguidos são regularidade (funcionamento de terça a domingo), acessibilidade (democratização do espaço, abrindo as portas aos diversos segmentos da sociedade) e credibilidade (seleção de projetos culturais com pesquisa, planejamento e transparência).

Particularmente, com relação ao turista, a ação principal do CCBB Brasília para atraí-lo é um anúncio semanal em jornais e revistas, contendo a programação de maior destaque. E estar sempre na mídia. Há, também, o ônibus gratuito do CCBB que circula de hora em hora e percorre grande parte do eixo monumental, local de muita visitação turística, passando, ainda, pelos setores hoteleiros sul e norte. Além disso, a programação mensal do Centro Cultural é distribuída nos hotéis.

\footnotetext{
${ }^{6}$ Idem, Nota 4.
} 
O trajeto percorrido pelo ônibus do CCBB foi estabelecido no sentido de procurar atender, além dos turistas, as pessoas que não têm meio próprio de locomoção, as pessoas que transitam pela Rodoviária do Plano Piloto e proximidades, as que trabalham na Esplanada dos Ministérios.

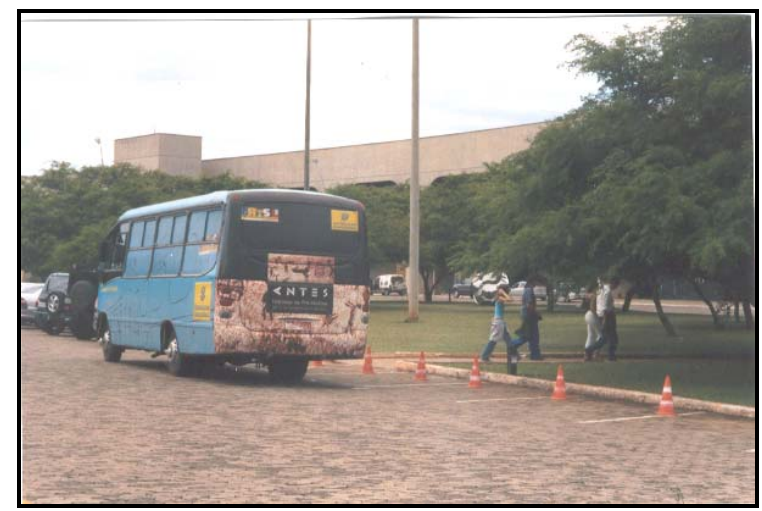

Fonte: Gilka Lemos/2005

Em 2004, primeiro ano de funcionamento do referido ônibus, mais de trinta mil pessoas usaram o serviço, demonstrando o acerto da decisão por esse investimento, que deve continuar durante o ano de 2005. O total de usuários do ônibus representou cerca de $8 \%$ do total de visitantes do CCBB Brasília em 2004 (404.093 pessoas) ${ }^{7}$.

Pesquisa realizada pelo próprio $\mathrm{CCBB}^{8}$ com seus freqüentadores revelou que, em 2004, o percentual de visitantes que utilizam veículo próprio caiu de $86 \%$ para $69 \%$, o que mostra a crescente afluência de pessoas com menor poder aquisitivo e a boa receptividade ao serviço de transporte gratuito disponibilizado (ou outras formas de transporte público). Outra mudança expressiva em relação ao ano anterior foi quanto à procedência do público: o percentual de visitantes que residem nas Cidades Satélites aumentou de 20\% para 39\%. Na pesquisa realizada para a elaboração desta monografia, o percentual apurado foi de $20 \%$.

\footnotetext{
${ }^{7}$ Ver Anexo 2 - Dados do Relatório Perfil de Público 2004, do CCBB Brasília.

${ }^{8}$ Idem, Nota 7.
} 
A seguir, encontram-se listados alguns aspectos do perfil do público visitante apurado pelo próprio CCBB Brasília:

- $19 \%$ vieram ao CCBB Brasília pela primeira vez;

- A maioria, 67\%, tem entre 20 e 49 anos de idade;

- Em torno de $48 \%$ possuem renda até $\mathrm{R} \$ 2.000,00$ e $12 \%$ têm renda entre $\mathrm{R} \$ 2.000,00$ e $\mathrm{R} \$ 3.000,00$;

- $27 \%$ são estudantes;

- $31 \%$ trabalham no setor público;

- 56\% possuem graduação ou pós-graduação;

- $69 \%$ vieram ao CCBB em veículo próprio;

- 39\% do público residem nas cidades satélites;

- $63 \%$ são mulheres;

- $58 \%$ são solteiros.

Ou seja, segundo dados coletados pelo $\mathrm{CBBB}$, mais da metade de seus freqüentadores são jovens e adultos (entre 20 e 49 anos); solteiros; mulheres e têm alto grau de escolaridade (mais da metade cursou a universidade). Do total dos freqüentadores, $27 \%$ são estudantes. Além do alto nível de renda, quase $70 \%$ dos visitantes possuem veículo próprio e 61\% residem na área central de Brasília. Portanto, trata-se de um público privilegiado em termos de renda, residência e escolaridade. Ademais, o CBBB parece ter um público cativo, considerando-se que menos de $20 \%$ ali se encontravam pela primeira vez.

\section{Processo de inscrição de projetos}

Anualmente, em geral nos meses de março ou abril, o CCBB abre as inscrições de projetos para a programação do ano seguinte. O processo de inscrição é via internet e os critérios de avaliação estabelecidos pelo Banco do Brasil são:

- Ineditismo (estréias nacionais nos centros culturais);

- Inovação (novos talentos e linguagens);

- Relevância cultural (representatividade do tema, da obra ou do artista em âmbito mundial); 
- Multidisciplinaridade (conexões entre modalidades artísticas);

- Brasilidade (valorização da arte e da cultura nacionais).

Observa-se que são critérios bastante amplos, destacando-se a multidisciplinaridade e, embora seja realçada a brasilidade, também se enfatiza a representatividade em nível mundial.

As propostas recebidas sofrem análise detalhada de seu conteúdo sob a ótica dos critérios divulgados e também com relação aos aspectos de qualidade, adequação físico-operacional e orçamentária. São avaliados trabalhos nas áreas de música, artes plásticas, teatro, cinema e vídeo, Programa Educativo, dança e "idéias" (seminários, debates, palestras).

A grade de programação é, então, sugerida e, de acordo com o orçamento definido pela Diretoria de Marketing e Comunicação do Banco do Brasil, um determinado número de projetos é escolhido e fará parte da programação dos três Centros Culturais em funcionamento. A responsabilidade pela execução de cada projeto selecionado fica a cargo da produção do mesmo.

\section{Programação}

A programação dos Centros Culturais alia lazer e conhecimento, cultura e diversão, itens que constituem a marca do CCBB.

Os investimentos do Banco do Brasil na programação dos Centros Culturais têmse elevado a cada ano. Em 2003, foram da ordem de R 27 milhões. Em 2004, R\$ 30 milhões e, para 2005, estão previstos investimentos em torno de $\mathrm{R} \$ 40$ milhões.

Além dos projetos escolhidos previamente pelo processo seletivo descrito no item anterior, e dependendo do orçamento extra que se consiga, outros eventos podem vir a fazer parte da programação anual, normalmente produções artísticas locais. 
O CCBB Brasília pretende, ainda, realizar pelo menos dois eventos de grande porte por ano, abertos ao público, um deles sempre no dia do aniversário do Centro Cultural, em 12 de outubro. Provavelmente shows de música.

\section{Programa Educativo}

É um dos principais projetos desenvolvidos, não só pelo CCBB Brasília como também pelas unidades do Rio de Janeiro e São Paulo. Em Brasília, o programa atende diretamente as escolas públicas e privadas da cidade e entorno, através da arte-educação. Os estudantes recebem material impresso e contam com o apoio de monitores devidamente treinados para as visitas às exposições e demais atividades realizadas no Centro Cultural. O Programa Educativo, bem como os demais projetos que fazem parte da programação dos Centros Culturais, são produzidos por empresas contratadas, de acordo com os projetos selecionados a cada ano.

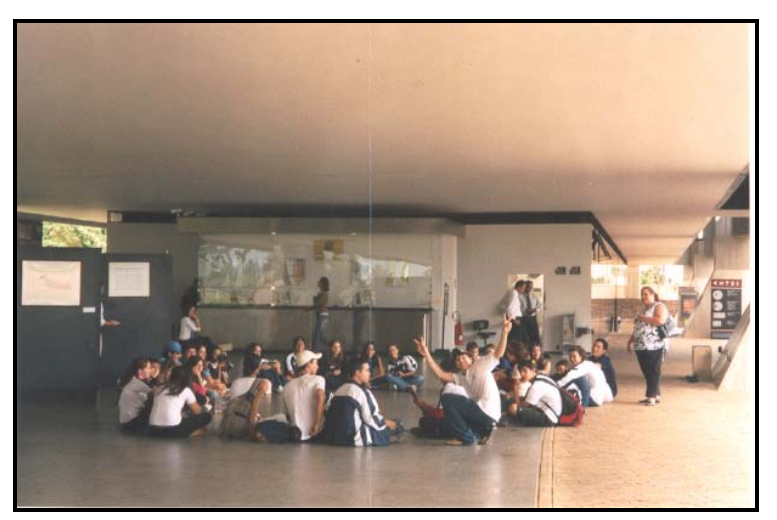

Fonte: Gilka Lemos/2005 


\subsection{O público freqüentador do CCBB Brasília}

A aplicação de questionário aos freqüentadores do CCBB Brasília procurou verificar dados objetivos como sexo, idade, profissão, estado civil, grau de instrução, procedência (se moram em Brasília ou não) e, no caso de morador de Brasília, o local de residência, dado importante para indicar, em boa medida, o estrato social a que pertence. Foram coletadas, também, informações sobre a freqüência das visitas e as preferências com relação à programação oferecida.

Além disso, foram formuladas questões abertas com o intuito de obter a opinião desses freqüentadores sobre o CCBB Brasília como atrativo turístico da cidade, bem como sobre a relação existente entre turismo e lazer. As respostas a essas questões serão comentadas mais adiante, no item 2.3.

Os principais resultados apurados, extraídos das tabelas que contêm a tabulação dos questionários (Apêndice 3), estão listados e comentados a seguir:

\section{Amostra: 150 questionários aplicados (100\%)}

\section{Residência:}

- $67 \%$ moram na área central de Brasília (100 pessoas):

Asa Norte (40); Lago Sul (19); Asa Sul (18); Sudoeste (6); Cruzeiro (5); Octogonal (2); Lago Norte (4); SHN (1); SMU (4) e Plano Piloto (1);

- 20\% moram nas Cidades Satélites (30 pessoas): Guará (5); Gama (3); São Sebastião ( 3); Sobradinho (3); Taguatinga (3); Brazlândia (2); Candangolândia (2); Riacho Fundo (2); Águas Claras (1); Ceilândia (1); Jardim Botânico (1); Núcleo Bandeirante (1); Paranoá (1); Samambaia (1) e Santa Maria (1);

- $9 \%$ não residem em Brasília (14 pessoas);

- $4 \%$ não informaram bairro, região administrativa ou cidade satélite (6 pessoas). 


\section{Profissão:}

- $30 \%$ são Estudantes (45 pessoas);

- $9 \%$ são Servidores públicos (14 pessoas);

- $\mathbf{5 \%}$ são Professores (7 pessoas);

- $4 \%$ são Jornalistas (6 pessoas);

- Menos de 4\%, cada uma: Artistas plásticos (4), Administradores (4), Advogados (4), Aposentados (4), Arquitetos (3), Psicólogos (3), Publicitários (3) e outras, conforme tabela constante do Apêndice 4.

- 3\% não responderam (5 pessoas).

Sexo:

- $59 \%$ são mulheres (89 pessoas);

- $41 \%$ são homens (61 pessoas).

\section{Estado civil:}

- $59,3 \%$ são solteiros ( 89 pessoas);

- $32 \%$ são casados/vivem com companheiro (48 pessoas);

- 7,3\% são descasados (11 pessoas);

- $1,3 \%$ são viúvos (2 pessoas).

\section{Grau de Instrução:}

- $67 \%$ têm o nível superior (100 pessoas), dos quais 36\% são pós-graduados;

- 31\% têm o nível médio (46 pessoas);

- $1 \%$ tem o nível fundamental (2 pessoas);

- $1 \%$ não respondeu (2 pessoas).

\section{Idade:}

- $17 \%$ têm menos de 20 anos (26 pessoas);

- 35\% têm entre 20 e 29 anos (53 pessoas);

- $\mathbf{1 7 \%}$ têm entre 30 e 39 anos (25 pessoas); 
- $15 \%$ têm entre 40 e 49 anos (22 pessoas);

- $13 \%$ têm entre 50 e 59 anos (19 pessoas);

- 3\% têm 60 anos ou mais (5 pessoas).

A amostra confirma, em boa medida, os dados levantados pelo próprio Centro Cultural, comentados no item 2.1: mais da metade dos freqüentadores é constituída por jovens e adultos (entre 20 e 49 anos); solteiros; mulheres; pessoas com alto grau de escolaridade (67\% cursaram a universidade) e $67 \%$ residem na área central de Brasília. Portanto, trata-se de um público privilegiado em termos de residência, escolaridade e, provavelmente, de renda. Destaque-se a grande participação de estudantes (30\%) no total dos freqüentadores.

Pode-se dizer que o público espontâneo freqüentador do CCBB Brasília é, realmente, bastante diversificado. No que se refere à idade, está bem distribuído dentro de uma ampla faixa que varia entre os 18 e os 60 anos. Quanto à profissão, apesar de 1/3 da amostra ser formada de estudantes, o restante encontra-se bastante pulverizado entre mais de 40 profissões, conforme tabela constante do Apêndice 4. Esse público possui, também, bom grau de instrução: a maioria tem curso superior ou pós-graduação, sendo raros os que não concluíram o nível médio. Quanto ao local de moradia, ainda que $67 \%$ dos visitantes residam na área denominada "central" de Brasília, estão distribuídos por vários de seus setores. Da mesma forma, os visitantes de cidades satélites distribuem-se por diversas delas e os turistas visitantes provêm de diferentes estados.

Vale destacar que os turistas, representantes de 9\% da amostra de público (14 pessoas), apresentam algumas diferenças em relação ao perfil geral do público freqüentador do CCBB (Apêndice 9): dentre as diversas profissões registradas, apenas 1 estudante (7\%) foi encontrado; a faixa etária está mais concentrada entre os 30 e 49 anos (58\%); os homens aparecem em percentual significativamente superior (64\%) ao de mulheres e o grau de instrução é mais elevado (79\% têm curso superior ou pós-graduação). 


\section{Freqüência das visitas ao CCBB:}

- $40 \%$ Eventualmente (60 pessoas);

- $19 \%$ Quinzenalmente (28 pessoas);

- $18 \%$ Mensalmente (27 pessoas);

- $10 \%$ Primeira vez (15 pessoas);

- $9 \%$ Semanalmente (14 pessoas);

- 4\% Outras (6 pessoas): anual (3), diária (1), não responderam (2).

Nos resultados mostrados neste item, é importante ressaltar que cerca de 30\% do público freqüenta o local pelos menos quinzenalmente, confirmando os dados comentados anteriormente, no sentido de que o CCBB Brasília já tem um público cativo expressivo. Nesta direção, também se mostra significativa a taxa de renovação desse público (10\%), representada pelos que visitaram o Centro Cultural pela primeira vez.

\section{Com soube do CCBB?}

- 41\% Pela mídia: jornal e outros meios de comunicação (62 pessoas);

- $34 \%$ Pelas pessoas: amigos, família, escola, trabalho etc. (51 pessoas);

- $14 \%$ Não responderam (21 pessoas);

- 11\% Outros: no CCBB RJ, pelo prédio, pelo ônibus do CCBB, veio a trabalho etc. (16 pessoas).

Neste item, observa-se que a propaganda "boca-a-boca" é quase tão importante quanto a mídia convencional, o que denota o elevado grau de satisfação do público com relação aos eventos e serviços oferecidos pelo CCBB Brasília. Isso também se encontra demonstrado nos resultados da pesquisa de satisfação realizada pelo próprio Centro Cultural': o índice médio geral apurado foi de 4,41 pontos, numa escala de 1 a 5 . Como destaque apontado pelos clientes, está a grade de eventos.

\footnotetext{
${ }^{9}$ Idem, Nota 7.
} 


\section{Motivo principal da visita ao CCBB}

- 76\% Exposição/Evento/Espetáculo atual (125 indicações);

- 11\% Baixo valor/gratuidade do ingresso (19 indicações);

- 10\% Outros: Biblioteca, Café e Livraria, Cinema, Palestras etc. (16 indicações);

- 2\% Conhecer o local (3 indicações);

- $1 \%$ Prédio projetado por Niemeyer (2 indicações).

Obs.: Questão aberta com total de respostas=165 (Ver Apêndice 5).

Esses resultados estão em consonância com os dados do próprio CCBB ${ }^{10}$, indicando que a área de exposições tem sido, historicamente, a responsável por atrair o maior número de freqüentadores ao Centro Cultural (42\% em 2004).

Nos períodos em que foi realizada a pesquisa, durante o mês de novembro/2004. estavam acontecendo outros eventos simultâneos às exposições já mencionadas: na semana de 2 a 7, uma retrospectiva da obra do cineasta argentino Hector Babenco e espetáculos da companhia de teatro de bonecos mineira Giramundo; na semana de 23 a 28, uma mostra de documentários de Sílvio Tendler e o $37^{\circ}$ Festival de Brasília do Cinema Brasileiro.

Confirmando o perfil privilegiado do público, o item "baixo valor/gratuidade do ingresso" foi apontado como motivo da visita por apenas $11 \%$ dos informantes.

\section{Eventos que mais interessam na programação do CCBB Brasília}

19\% Exposições (131 indicações);

16\% Cinema (111 indicações);

15\% Teatro (103 indicações);

12\% Música popular (81 indicações);

10\% cada um: Dança (69) e Música Erudita (67);

9\% cada um: Debates (65) e Oficinas (61).

Obs.: Questão aberta com total de respostas=688. Ver Apêndice 6.

\footnotetext{
${ }^{10}$ Idem, Nota 7.
} 
Apesar de terem sido listadas as opções constantes da programação do Centro Cultural e de ter sido solicitada a ordenação das mesmas de acordo com a preferência do pesquisado, nem sempre esse critério foi obedecido. Alguns apenas assinalaram aquelas que Ihes interessavam, sem priorizar cada uma em relação às outras.

De qualquer modo, observa-se uma distribuição bastante equilibrada das preferências do público, indicando o acerto do CCBB na escolha de sua programação, na ênfase dada à diversidade das atividades culturais que oferece. Exposições, cinema e teatro, nesta ordem de prioridade, foram as opções mais votadas.

\subsection{CCBB, turismo e lazer}

Com o objetivo de saber se o público freqüentador do CCBB Brasília vê esse espaço como um atrativo turístico, foi solicitada a indicação dos três pontos turísticos mais importantes da cidade e, em seguida, perguntou-se por quê o CCBB estaria (ou não estaria) entre os indicados. Os resultados estão listados a seguir:

\section{Principais pontos turísticos de Brasília}

- $15 \%$ Torre de TV (66 pessoas);

- 14\% Catedral (64 indicações);

- 11\% Esplanada dos Ministérios (50 indicações);

- 8\% Praça dos 3 Poderes (37 indicações);

- 6\% cada um: CCBB (27 pessoas); Congresso Nacional (25 indicações);

- $5 \%$ Ponte JK (22 indicações);

- 4\% cada um: Palácio da Alvorada (18), Teatro Nacional (17), Parque da Cidade (16);

- 3\% cada um: Memorial JK (14), Palácio do Itamaraty (11); 
- 2\% cada um: Catetinho (10), Ermida Dom Bosco(10), Lago Paranoá (10);

- Menos de 2\% cada um: Pontão do Lago Sul (7), UnB (4), Igreja Dom Bosco (3), Ponte Costa e Silva (3), Parque da Água Mineral (3), Palácios (3), Conjunto Nacional (2), Palácio do Planalto (2), Cine Brasília (2), Feira da Torre (2) e outros. Ver Apêndice 7.

As respostas revelam que o CCBB foi lembrado por apenas 6\% dos respondentes (27 pessoas), o que seria de se esperar diante de tantos monumentos arquitetônicos de grande visibilidade existentes na cidade (a Torre de TV, atração mais indicada, foi responsável por $15 \%$ do total).

Por outro lado, o fato de a pesquisa ter sido realizada no próprio CCBB pode explicar a posição alcançada no ranking dessas indicações ( $5^{\circ}$ lugar), uma vez que, mesmo se tratando de uma atração do ponto de vista da arquitetura (é um imponente e moderno prédio de Niemeyer, tombado pelo Instituto do Patrimônio Histórico e Artístico Nacional - Iphan), situa-se fora do circuito turístico de maior importância na cidade, composto pelo Palácio da Alvorada e Eixo Monumental, local onde se encontram os principais pontos mencionados pelos pesquisados: Torre de Televisão, Catedral, Esplanada dos Ministérios, Praça dos Três Poderes, Congresso Nacional, Teatro Nacional, Memorial JK e Palácio do Itamaraty. De qualquer forma, o Centro foi mais lembrado do que os Palácios, a Ponte JK, o Cine Brasília, Catetinho e muitos outros monumentos considerados importantes dentro do conjunto.

As duas indicações para o CCBB Brasília dadas por turistas fundamentaram-se na variedade da programação e no oferecimento de diversão, de um ambiente agradável. Também para eles, o CCBB Brasília alcançou a quinta posição no ranking dos mais importantes pontos turísticos da cidade, com duas indicações, e dividiu essa posição com outros monumentos como a Ponte JK e o Palácio da Alvorada (Apêndice 9). As quatro primeiras indicações também coincidem com o 
resultado geral (Catedral, Torre de TV, Esplanada dos Ministérios e Praça dos Três Poderes).

Conforme tabela constante do Apêndice 8, a promoção da cultura envolve grande parte dos motivos que levaram os informantes a indicar o CCBB como importante ponto turístico de Brasília. Outra justificativa bastante apresentada refere-se à variedade da programação oferecida e sua qualidade. Foram citadas, também, razões como a arquitetura do prédio, o preço acessível/gratuidade dos ingressos, a qualidade dos eventos, o ambiente agradável e a oferta de divertimento/lazer cultural. Pode-se dizer que esse é um público freqüente: $37 \%$ vão ao CCBB Brasília pelos menos quinzenalmente e 33\% o fazem mensalmente.

A partir das justificativas apresentadas sobre a não inclusão desse espaço cultural como importante ponto turístico da cidade ${ }^{11}$, fica evidente que a opinião de 25 pesquisados (16,7\%) é no sentido de que, com o tempo, o CCBB figurará naquela lista: o que Ihe falta para tanto, agora, seria tornar-se um espaço tradicional de veiculação da cultura. Esse entendimento também foi manifestado por boa parte do universo de turistas (5 pessoas - 35,7\%), conforme tabela constante do Apêndice 9.

O termo cultura, sob a perspectiva sócio-antropológica, é um conjunto de instrumentos, objetos, edifícios, padrões de comportamento, valores, crenças, conhecimentos, costumes, que caracterizam ou distinguem um grupo social, uma etnia, uma sociedade.

Tal perspectiva se alinha com o pensamento de Featherstone (1995: 179) que , a esse respeito, afirma:

"o termo 'cultura' tem sido usado de várias maneiras para designar normas, idéias, crenças, valores, símbolos, linguagens e códigos. Pode também assinalar o processo de desenvolvimento espiritual e intelectual da pessoa, ou os redutos e

\footnotetext{
${ }^{11}$ Ver Apêndice 3 - Planilha Geral - Parte 4.
} 
práticas artísticas e intelectuais especializadas (a esfera cultural e a alta-cultura), e ainda todo o modo de vida de um grupo, povo ou sociedade (a concepção antropológica)".

Alguns autores têm assinalado a importância de se associar cultura e turismo. Segundo Pires (2002: 66-67),

"quem viaja não quer fazer apenas uma coisa, porém várias, quantas the propiciem o tempo disponível e as facilidades. Tanto mais isso é verdade quanto mais o mundo de hoje valoriza o lazer. (...) estudos constataram que as pessoas viajam por diferentes motivos, mas, mesmo não tendo particular interesse em cultura, os turistas acabam visitando atrações culturais, se forem oferecidas facilidades para tanto".

Ainda de acordo com Pires, tal realidade propiciou uma definição de turismo cultural mais ampla, tanto no que concerne aos motivos primeiros que ensejam viagens, quanto ao conteúdo daquilo que se considera cultura: "visitas de pessoas de fora da comunidade receptora motivadas completamente ou em parte por interesses na oferta histórica, artística, científica ou no estilo de vida, tradições da comunidade, religião, grupo ou instituição" (Silberberg, 1995 citado por Pires, 2002: 68).

Para Susana Gastal (2001: 35),

"o turismo cultural era, até há bem pouco, apenas uma das segmentações pelas quais os teóricos e estatísticos procuram qualificar as diferentes motivações nos deslocamentos das pessoas. Hoje, o fator cultural ganhou novos espaços e está presente nos projetos desde a concepção inicial, no seu planejamento, e nos desdobramentos da gestão e do marketing turístico. As novas exigências do público consumidor - os turistas - nos levam a repensar a Cultura, desta forma, não apenas como a motivação da viagem, mas como o 'insumo' específico, ao lado dos atrativos naturais e dos serviços, nas formatações de produtos turísticos".

Os turistas estão sempre ávidos por encontrar os marcos culturais dos lugares visitados: "o olhar é construído através de signos, e o turismo abrange uma 
coleção de signos", conforme John Urry (2001: 18). Um espaço cultural como o CCBB Brasília detém requisitos bastantes para se transformar em objeto de especial atenção do turismo, tanto pela sua arquitetura quanto pelo uso dessa edificação para a realização de manifestações artístico-culturais e como espaço de convivência entre as pessoas. E o turismo, por sua vez, está intrinsecamente relacionado ao lazer.

Conforme Jofre Dumazedier (2000: 34),

"o lazer é um conjunto de ocupações às quais o indivíduo pode entregar-se de livre vontade, seja para repousar, seja para divertir-se, recrear-se e entreter-se ou, ainda para desenvolver sua informação ou formação desinteressada, sua participação social voluntária ou sua livre capacidade criadora após livrar-se ou desembaraçar-se das obrigações profissionais, familiares e sociais".

Nas respostas à questão "Pra você, qual é a relação existente entre lazer e turismo?", ficou claramente demonstrada essa estreita ligação (Apêndice 3): para $30 \%$ dos pesquisados (45 pessoas), o turismo é uma forma de lazer; 15\% (22 pessoas) resumiram a resposta em uma só palavra: total, complementar, íntima, grande, importante, intrínseca, direta, visceral, muita; outros 19\% (28 pessoas) referiram-se à diversão ou ao prazer como elementos de ligação do lazer com o turismo.

De acordo com Mantero (2000: 190),

"os espaços que melhor permitem o exercício da função do lazer são os destinados à cultura. A cultura é, primordialmente, uma atividade simbólica, vivencial que integra, que dá unidade, que oferece significados e nos faz participar de uma comunidade a partir da inserção, seja na unidade familiar, seja na unidade social na qual estamos integrados".

O aumento de público nas exposições de arte nos últimos anos mostra uma tendência de "popularização" dos museus, de adoção de uma política cultural voltada para a democratização do uso desse espaço e do acesso à arte: 
"o consumo cultural espalhou-se para além das camadas privilegiadas da população facilitado pela indústria cultural. As estatísticas registram que há mais pessoas com aparelhos de som e videocassetes em suas casas, os canais de televisão encarregam-se de divulgar museus e exemplares monumentais da arquitetura, e as grandes exposição de artes plásticas têm carreado multidões por suas roletas, em roteiros ao redor do mundo" (Ashworth, 1995 citado por Gastal, 2001: 37).

Os museus mudaram, passaram a oferecer várias opções culturais e de entretenimento, atraindo um público ávido por informação e lazer ao mesmo tempo. O museu da atualidade é, pois, um Centro Cultural, cujo espaço abriga também áreas destinadas a serviços (cafés, restaurantes, livraria) e às diversas atividades de lazer cultural e de entretenimento (exposições, teatro, música, cinema, biblioteca, debates, palestras).

Observa-se, também, que a implantação de museus e centros culturais tem sido objeto de disputa pelas cidades, uma vez que esses espaços atraem o turismo para o lugar onde estão situados, tornando-se um símbolo do lugar em que se inserem e promovem uma imagem positiva para a cidade, além de elevar a autoestima e o sentimento de pertencimento da população local. Nesse sentido, os CCBBs têm sido objeto de desejo de muitas cidades, de diversas partes do país (Porto Alegre, Curitiba, Florianópolis, Goiânia e Belém, por exemplo) ${ }^{12}$.

Um Centro Cultural, no entendimento de Camargo (2004), é um espaço de lazer importantíssimo para a cultura urbana e para a sociabilidade das pessoas, despertando o sentimento de pertencer à cidade, o sentimento de identidade, a cidadania.

No caso do CCBB Brasília ${ }^{13}$, percebeu-se que o público já está freqüentando o local mesmo sem verificar antes a programação que está em cartaz, porque sabe

\footnotetext{
${ }^{12}$ Idem, Nota 4.

${ }^{13}$ Idem, Nota 4.
} 
que sempre vai encontrar uma atividade interessante para fazer ou mesmo poder desfrutar de um espaço bastante agradável, com várias outras opções como a livraria, o café, a praça de eventos, o jardim. E há a intenção de se ampliar esse espaço de convivência.

Para Carlos Delphim (2004),

"o patrimônio cultural de um povo, do ponto de vista material, são as obras, objetos, documentos, edificações, espaços utilizados para manifestações artísticoculturais, conjuntos urbanos e sítios de valor histórico, paisagístico, artístico, arqueológico, paleontológico, ecológico e científico. Do ponto de vista imaterial, inclui as formas de expressão de um povo, seus modos de criar, de fazer, de viver, de agir, seus conhecimentos, costumes e instruções".

Assim, ao assumir a condição de espaço de uso coletivo, o CCBB passa a ser um representante da identidade local e, como tal, a ser percebido como patrimônio cultural. E patrimônio cultural, como já foi dito antes, é objeto especial de atenção do turismo na atualidade. 


\section{Considerações finais}

Este trabalho teve como objetivo compreender o papel desempenhado pelo CCBB dentro do roteiro turístico cultural de Brasília a partir da identificação e análise de seu público freqüentador, bem como das informações obtidas sobre o seu funcionamento e sobre a programação cultural que oferece.

Como mostram os dados quantitativos da pesquisa realizada, o contingente de turistas representou apenas 9\% da amostra coletada. Entretanto, a tendência é de que esse público aumente gradativamente, na medida em que o CCBB se firme como um espaço cultural importante da cidade, passando, então, a fazer parte da sua tradição. Para que um espaço cultural se torne atrativo turístico, são necessários o seu reconhecimento e valorização pela população local.

As ações do Banco do Brasil na área da cultura visam promover a multiplicidade cultural, apoiando e realizando projetos inovadores que estimulam a produção artística e as atividades educacionais. Ao mesmo tempo, elas têm o objetivo de reforçar a imagem da instituição junto aos seus clientes, impulsionando a oferta de produtos e serviços.

Os Centros Culturais Banco do Brasil têm sido o mais importante instrumento utilizado na busca desses objetivos. Eles têm-se tornado importantes espaços culturais nas cidades onde se instalam. Em Brasília, o CCBB parece não fugir à regra: ao oferecer uma programação regular bastante diversificada e de indiscutível qualidade, tem recebido um público freqüentador também variado, composto em sua maioria por pessoas da cidade mas, também, por turistas, que buscam o lazer cultural.

Para estimular a freqüência de turistas ao local, a administração do CCBB tem realizado ações de divulgação constante de sua programação na mídia e junto aos 
hotéis da cidade, além de oferecer transporte gratuito que circula nas localidades mais freqüentadas por turistas (o Eixo Monumental). A título de colaboração com vistas à otimização do serviço de transporte oferecido, fica a sugestão de que o funcionamento do ônibus não se restrinja ao período das exposições e, ainda, que seja instalada uma marca permanente nos pontos por onde passa esse ônibus, no estilo "aqui passa o ônibus do CCBB". 